\section{Pieces of mind: more for the clinician than the academic}

\section{Stuart Sutherland}

Longman Dictionary of Psychology and Psychiatry.

Edited by Robert M. Goldenson and Walter D. Glanze.

Longman: 1984. Pp. 816.

£29.50, \$39.95.

THERE is a real need for an up-to-date dictionary of psychology; as far as I know, none has been published since 1978 . Despite the fanfare in the blurb (" 21,164 entries or headwords, twice to five times the number of other dictionaries in these fields'), the Longman Dictionary of Psychology and Psychiatry fails to fill this gap.

The psychological entries contain many errors and omissions. The latter include many terms in common use, such as "twoprocess learning theory", "episodic memory", "iconic storage" and - less common, but still important - "anorthoscope". Students frequently confuse "focussing" with "fixating", but this book will not help them: "fixating"' is not the "focussing of both eyes on a single object", it is positioning the eyes in such a way that the same object falls at the centre of each fovea (the same error recurs elsewhere in the Dictionary). The definition of "receptive field" would have been correct fifty years ago, but does not capture the way the expression is most often used today. Many Pavlovian terms are too loosely defined - "Pavlovian inhibition" is not the "suppression of a response", it is a process that may lead to the suppression of a response; the unconditioned stimulus follows the conditioned one, it is not merely paired with it and so on.

A half-hearted attempt is made to cover some of the fields that are now relevant to psychology, for example linguistics, but oddly there appear to be almost no terms from computing science or artificial intelligence: the definition of "heuristic" is grossly misleading since its technical sense is omitted.

The Dictionary appears to do better with psychiatric terms, of which it includes many more than the latest edition of Oxford University Press's Psychiatric Dictionary (1981); hence, it may be of more use to psychiatrists than to psychologists. But when confronted with this weighty volume, members of both professions may well wish that progress in their respective fields had been commensurate with the amount of jargon they have generated.

Stuart Sutherland is Director of the Centre for Research on Perception and Cognition at the University of Sussex.

\section{Environmental issues}

\section{Timothy O'Riordan}

Dictionary of the Environment, 2nd Edn. By Michael Allaby.

Macmillan, London: 1984. Pp.529. Hbk

$£ 25$; $p b k £ 7.95$.

Directory for the Environment:

Organisations in Britain and Ireland

1984-5.

Edited by Michael J.C. Barker.

Routledge \& Kegan Paul: 1984. Pp.281.

$P b k$ £8.95, \$19.95.

PRODUCING a dictionary must be a labour of love. The intellectual rewards are relatively small and the scope for criticism over omissions or nuances of meaning is considerable. Michael Allaby's second edition of Dictionary of the Environment comes six years after his first. The contents are much fuller and he has benefitted from the advice of a small company of distinguished friends. The entries are mostly very short, covering clearly and competently all the basic physical, chemical, biological and geographical phenomena. The book's conciseness is a great asset: some 6,000 entries are crowded into 529 pages. However some entries are superfluous - or at least appear so because of the apparent determination to be brief. For example "Environment, Department of" is described as "Department of the Environment" - no mention as to country, or function or date of birth. Similarly EPA is merely described as "Environmental Protection Agency". This is hardly helpful, and a relatively modest expansion of information would have paid dividends.

There are also some curious omissions. There is no entry for environmentalism or environmentalist, nor is there anything under acid rain or acid deposition. There is an entry under environmental quality standards (an American term now embraced by the European Commission), but nothing for environmental quality objectives, a concept much protected by British regulatory authorities. In similar vein, the entry under "best practicable means" only connects it to air pollution control when it now has much wider application. The notorious phrase "as low as reasonably achievable", now in such dispute in the wake of events at Sellafield, does not appear at all. This is a dictionary of specifics rather than concepts.

Michael Barker's Directory is altogether a more worthy book, even though it was probably easier to collate than Allaby's Dictionary. Barker has sought to compile a list of all official and voluntary organizations which have something to do with environmental management and environmental protection. He appears to have sought his information with care but within a limited budget: inevitably some of the entries are piecemeal and inaccurate. As this is to be the first of a series, greater comprehensiveness and accuracy should be attained later on.

The entries are listed in alphabetical order. Each provides a name, address, contact phone number and a brief description of activities together with a list of relevant publications. There is a good subject index which allows the reader to look up the variety of organizations interested in a particular theme. For example there are 34 entries under "energy conservation" and 67 under "nuclear power". Maybe next time Barker will delve into the Civil Service Yearbook to seek out the sub-compartments of government departments responsible for particular aspects of environmental matters.

Nevertheless this is a valiant and valuable production. Barker has uncovered all kinds of interesting groups. What about HOOVES, which aims to make roads a safer place for horses and to encourage the provision of livery stables and "parking" places for horses in cities? Or Green Deserts, which promotes and participates in desert reclamation schemes and seeks to bring the facts about desert reclamation to the attention of the general public? Students and researchers should take note: many of the organizations listed provide information upon request and they are often well qualified and motivated to do so. Here is an excellent reference book.

Timothy O'Riordan is Professor of Environmental Sciences at the University of East Anglia.

Copies of articles from this publication are now available from the UMI Article Clearinghouse.

Yes! I would like to know more about UMI Article Clearinghouse. 1 am interested in electronic

ordering through the following system(s):

$\square$ DIALOC/Dialorder $\quad \square$ ITT Dialcom

$\square$ OnTyme $\square$ OCLC ILL Subsystem

$\square$ Other (please specify)

I am interested in sending my order by mail.
Please send me your current catalog and user instructions for the system(s) I checked above.

Name

Title.

Institution/Company

Department

Address.

City___ State__ Z Z Z

Phone

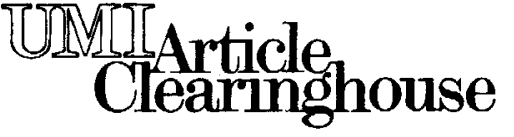

Mail to: University Microfilms International 300 North Zeeb Road, Box 91 Ann Arbor, MI 48106 